\title{
Angina Bullosa Hemorrhagica - An Uncommon Oral Lesion
}

\author{
Lt Col Indranil Mukhopadhyaya ${ }^{1}$, Col S. K. Rath ${ }^{2}$ \\ ${ }^{1} \mathrm{MDC}$, Danapur, Bihar, India, ${ }^{2} \mathrm{CO}, 9$ CDU, Dharmashala, Himachal Pradesh, India
}

Email for correspondence: drrathfamily@yahoo.com

\begin{abstract}
Angina bullosa hemorrhagica $(\mathrm{ABH})$ is used to describe an acute, benign subepithelial oral mucosal blood-filled vesicle/vesicles or blisters. Intraorally, a large $(2.0 \mathrm{~cm}$ diameter $)$ blood filled, painless, and raised round vesicle with dark red in color was found in the posterior to the hard palate, extending toward soft palate of the patient. On the basis of history, clinical appearance, and absence of any laboratory findings suggestive of bleeding disorder, a diagnosis of $\mathrm{ABH}$ was established and an excisional biopsy was planned with successful outcome and the same has been discussed in this present paper.
\end{abstract}

Key words: Angina bullosa hemorrhagica, blood-filled blister, bulla

\section{INTRODUCTION}

Angina bullosa hemorrhagica $(\mathrm{ABH})$ is used to describe an acute, benign subepithelial oral mucosal blood-filled vesicle/vesicles or blisters which is/are not due to any systemic disorders or hemostatic defects. The lesion was first named as traumatic oral hemophagocytosis in 1931. Later, Badham termed this as $\mathrm{ABH}$ in 1961. $\mathrm{ABH}$ is an uncommon and benign subepithelial disorder appearing as hematic blisters on the oral and oropharyngeal mucosa and no relation with any dermatological, hemostatic, or systemic condition. ${ }^{[1]}$ In 1994, Kirtschig and Happle named it "Stomatopompholyx hemorrhagica," as "angina" was an inadequate term for this disease. However, despite all the attempts in changing its name, $\mathrm{ABH}$ continues as the most commonly used term in the literature. ${ }^{[2]}$

The lesion is a rare in appearance or occurrence in oral cavity and many a times, it is confused with various systemic disorders such as mucous membrane pemphigoid, epidermolysis bullosa, and

\begin{tabular}{|l|l|}
\hline Quick Response Code & Article Info: \\
\hline doi: 10.5866/2018.10.10060 \\
\hline $\begin{array}{l}\text { Received: } 28-12-2017 \\
\text { Revised: } 22-01-2018 \\
\text { Accepted: 02-02-2018 } \\
\text { Available Online: 15-04-2018, 2018 (www. } \\
\text { nacd.in)@ NAD, 2018 - All rights reserved }\end{array}$ \\
\hline
\end{tabular}

herpetiform dermatitis. The lesion many a times is indistinguishable from blood dyscrasia such as thrombocytopenia, ecchymosis, and epistaxis. However, the isolated, rare occurrence, rapid healing in nature and absence of any deviation from systemic parameters, or hematocrit values are generally sufficient to rule out the lesion from above-mentioned systemic disorders. Here, a case report on $\mathrm{ABH}$ is presented where the case was diagnosed and treated by a dental surgeon in a Service Hospital setup.

\section{CASE REPORT}

A 42-year-old serving soldier reported to dental OPD, duly referred by Medical officer of the hospital with the complaint of sudden painless, large, and soft swelling in the palate immediately after eating the "jalebi" an Indian traditional hot and common sweet. He also reported that the swelling was gradually increasing in size [Figures 1 and 2]. $\mathrm{He}$ was absolutely asymptomatic before the occurrence of incidence except that he suffered from a small episode of cold 2 days back.

On taking history, his medical history was noncontributory. He has been a tobacco user in the form of cigarette for last 20 years and continuing till day.

On examination, individual was of average body weight, afebrile, fully oriented, and conscious whose vitals were found within normal limits. History of blood dyscrasia and other hematological disorders 
were also explored and were found to be normal. His dental and family history was unremarkable.

Intraorally, a large blood filled, painless, and raised round vesicle with dark red in color measuring about $2.0 \mathrm{~cm}$ in diameter was found in the posterior to the hard palate, extending toward soft palate [Figure 3]. Routine blood examination which includes complete blood count (CBC), prothrombin time, international normalized ratio, platelet count, and blood sugar (fasting and pp) was carried out to rule out any systemic cause or blood disorders.

On the basis of history, clinical appearance, and absence of any laboratory findings suggestive of bleeding disorder, a diagnosis of $\mathrm{ABH}$ was established and an excisional biopsy was planned

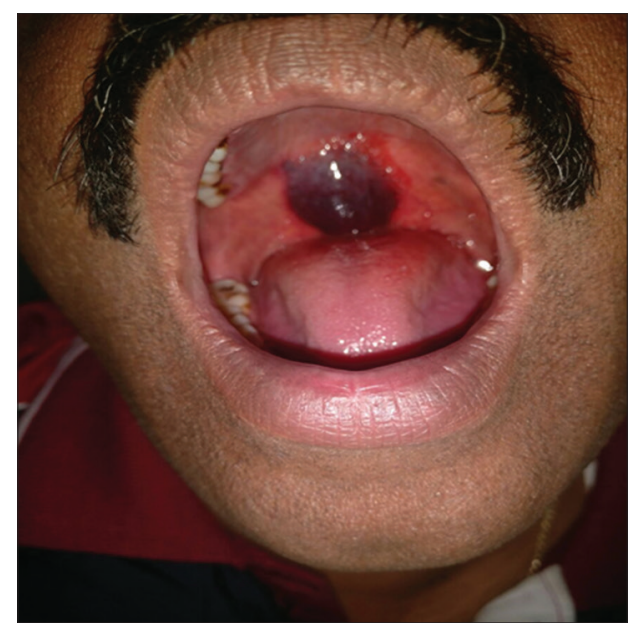

Figure 1: Clinical picture showing initial sign of the lesion on reporting

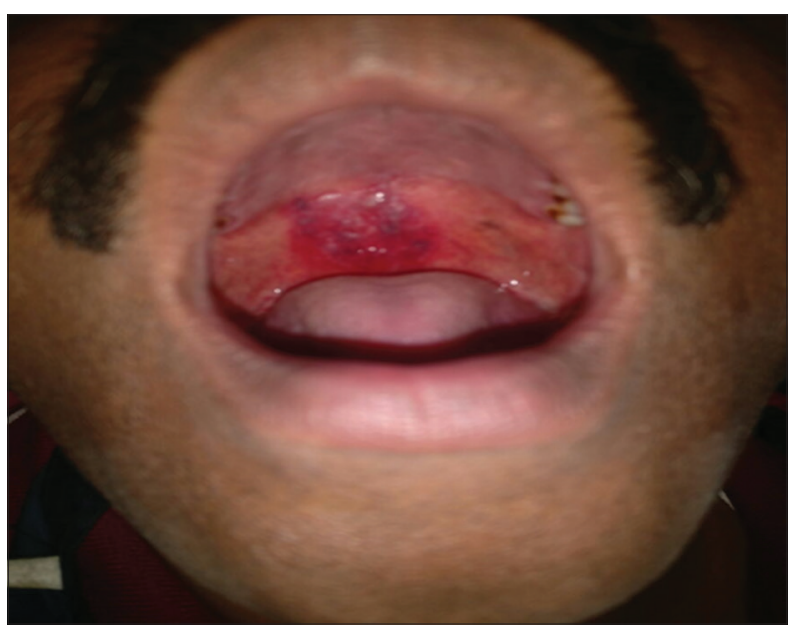

Figure 2: Clinical picture showing formation of blister after $24 \mathrm{~h}$ and pemphigus, bullous pemphigoid, bullous lichen planus, etc., were ruled out.

The patient was prescribed tab. levocetirizine $5 \mathrm{mg} 12$ hoursly a day, tab. Vitamin C $500 \mathrm{mg} 12$ hourly a day, and tab. paracetamol $500 \mathrm{mg} 6$ hoursly for 7 days. The patient was also advised $0.12 \%$ chlorhexidine for mouthwash 3-4 times a day for 7 days. The patient was counseled about the disease and healing of the lesion was closely monitored by follow-up after $24 \mathrm{~h}, 72 \mathrm{~h}$, and 7 days [Figure 4].

\section{DISCUSSION}

$\mathrm{ABH}$ is an idiopathic condition. Causes that have been mentioned in the literature are related to the minor trauma of hot foods, restorative dentistry, periodontal therapy, dental injections of anesthetics, steroid inhalers, and chlorhexidine

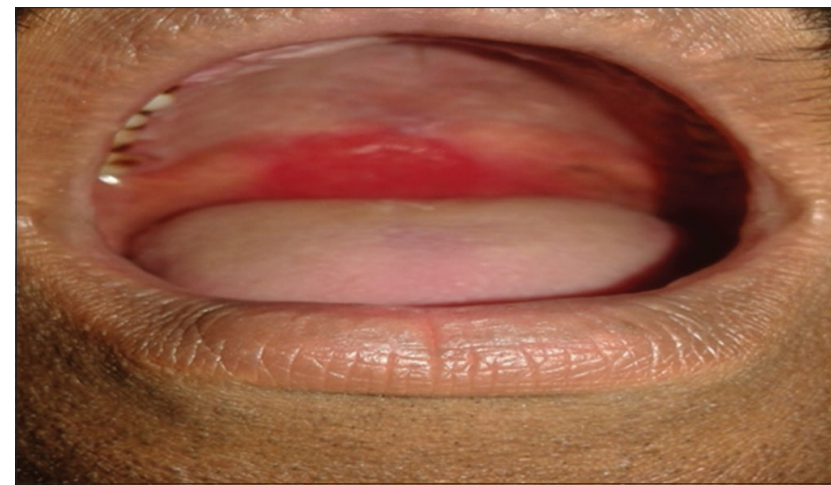

Figure 3: Clinical picture showing a large blood filled, painless, and raised round vesicle with dark red in color measuring about $2.0 \mathrm{~cm}$ in diameter found in the posterior hard palate, extending toward soft palate

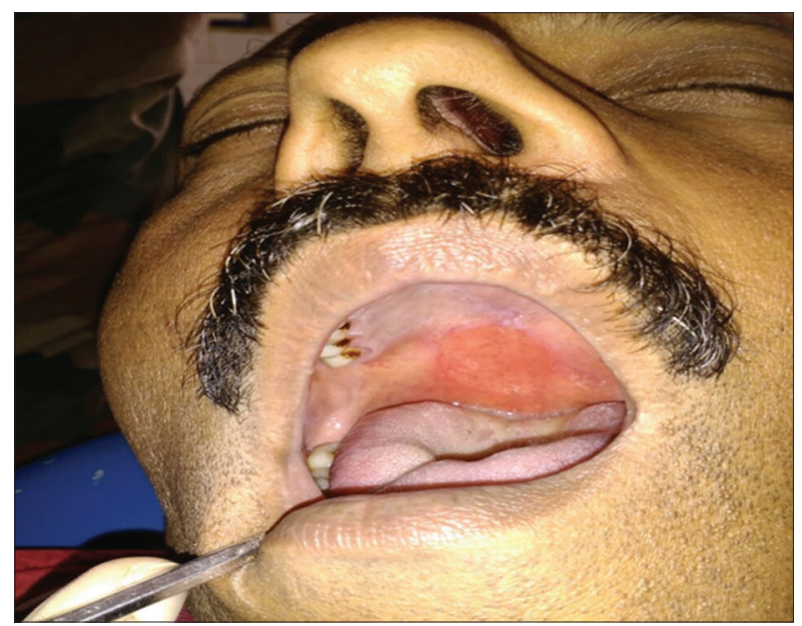

Figure 4: Clinical picture showing healing of the lesion after 7 days 
gluconate mouth rinse. Diabetes mellitus may be a contributing factor in developing $\mathrm{ABH}$. Some authors suggest mild trauma as the causative agent in $\mathrm{ABH}$ to break the epithelial-connective-tissue junction, causing bleeding of superficial capillaries, and resulting in the formation of a subepithelial hemorrhagic bullae. ${ }^{[3-6]}$

The blisters last only few minutes and then spontaneously rupture, leaving a shallow ulcer that heals without scarring, discomfort, or pain, as seen in both the present cases. The lesions reach an average size of $1-3 \mathrm{~cm}$ in diameter. The soft palate is the most commonly affected site. Occasional lesions have been reported in the buccal mucosa and tongue. The blisters last only for few minutes and then ruptures spontaneously, leaving a shallow ulcer that heals with no or little discomfort and pain, without any scar formation, as seen in the present case. The lesions reach an average size of $1-3 \mathrm{~cm}$ in diameter. The soft palate is the most commonly affected site. Occasional lesions have been reported in the buccal mucosa and tongue. ${ }^{[7,8]}$

\section{Pathophysiology}

The etiology remains obscure. $\mathrm{ABH}$ has been associated with constitutional predisposition, such as lose cohesion between the epithelium and the corium of mucosa, or weak anchorage of mucosa/ subepithelial blood vessels.

Few potential predisposing factors like arterial hypertension, diabetes mellitus, long-term use of inhaled steroid (especially when oral hygiene is not maintained) and viral episodes (such as pharyngitis, herpangina etc) are listed.

Although $\mathrm{ABH}$ is accepted as a benign disorder, some authors reported a choking or gagging sensation when the lesions are in the posterior pharynx or in the epiglottis. ${ }^{[9]}$ As a rare complication, acute upper airway obstruction was also reported. ${ }^{[10]}$ Given the clinical characteristics of this disease, a specific treatment is unnecessary in most cases, recommending a symptomatic treatment of the lesions. ${ }^{[8,11]}$ A complete blood test is necessary to rule out a possible systemic compromise while a histopathological analysis would be helpful in those cases with a complicated differential diagnosis.

The benign nature of the process should always be explained to the patients. ${ }^{[2]}$ Given the possible traumatic etiology, this should be avoided by establishing general measures and eliminating all possible irritants. In $\mathrm{ABH}$ patients with discomfort or pain, the treatment of the symptoms includes different drugs such as a mouthwash of benzydamine hydrochloride, several anti-inflammatory drugs, or even topical beclomethasone.

To avoid the superinfection of the ulcer resulting from theruptureoftheblister,ithasbeenrecommended rinsing with chlortetracycline. However, most authors support the use of chlorhexidine gluconate mouthwashes in concentrations between $0.12 \%$ and $0.25 \%$. To avoid possible recurrences, ascorbic acid and citroflavonoids have been suggested to be administered to the patients, without effective results reported. ${ }^{[3]}$

The general prognosis for $\mathrm{ABH}$ is good; however, large lesions and on the soft palate and oropharynx may cause a feeling of suffocation due to a compromise of the upper airway, which leads the patient to seek urgent attention and even compromises his or her life. Therefore, large blisters are recommended to be ruptured, $\mathrm{ABH}$ generates blood-filled blister; however, hematologic abnormalities may exhibit similar lesion as well. Hematological disorders might exhibit epistaxis, ecchymosis, and other signs. Thus, clinicians should pay attention to these signs. In case of $\mathrm{ABH}$, evaluation of $\mathrm{CBC}$ and hemostatic function result within normal range. In the patient of our report, the biopsy of ulcerative lesion was done and subepithelial cleft with chronic inflammation was observed in the results. Hemorrhagic fluid with a few inflammatory cells was observed in the aspiration biopsy of intact blister before breaking. In combination of thorough review of medical history, laboratory test, and biopsy, we diagnosed the patient as $\mathrm{ABH}$. Management of $\mathrm{ABH}$ includes reassuring patient, relief of pain, promotion of healing, and preventive treatment of secondary infection. The use of chlorhexidine gluconate was recommended as well.

\section{CONCLUSION}

$\mathrm{ABH}$ disorder is an extremely rare phenomenon and thus underreported. Recurrence has been reported to occur once or twice a year in approximately $30 \%$ of the affected people. Although $\mathrm{ABH}$ is a benign condition, some cases have been reported with acute upper airway obstruction because of rapidly expanding bulla/vesicle in posterior pharyngeal wall and epiglottis. Endotracheal intubation or tracheostomy or cricothyroidotomy requires to perform to establish airway and to save life of 
the patient. Therefore, a high level of suspicion is warranted on the part of dental surgeon who may be the first to encounter the lesion. It is important for the dentist to acknowledge this condition as to differentiate it from other oral vesicular processes with a poorer prognosis such as pemphigus vulgaris, mucous membrane pemphigoid, or certain hematological diseases.

\section{REFERENCES}

1. Badham NJ. Blood blisters and the oesophageal cast. J Laryngol Otol 1967;81:791-803.

2. Kirtschig G, Happle R. Stomatopompholyx hemorrhagica. J Am Acad Dermatol 1994;31:804-5.

3. Horie N, Kawano R, Inaba J. Angina bullosa hemorrhagica of the soft palate: A clinical study of 16 cases. J Oral Sci 2008;50:33-6.

4. Deblauwe BM, van der Waal I. Blood blisters of the oral mucosa (angina bullosa haemorrhagica). J Am Acad Dermatol 1994;31:341-4.
5. High AS, Main DM. Angina bullosa haemorrhagica A complication of long term steroid inhaler use. Br Dent $\mathrm{J}$ $1988 ; 165: 176-9$

6. De las Heras ME, Moreno R, Núñez M, Gómez MI, Ledo A. Angina bullosa hemorrhagica. J Dermatol 1996;23:507-9.

7. Stephenson P, Scully C, Prime SS, Daly HM. Angina bullosa haemorrhagica: Lesional immunostaining and haematological findings. $\mathrm{Br} J$ Oral Maxillofac Surg 1987;25:488-91.

8. Stephenson P, Lamey PJ, Scully C, Prime SS. Angina bullosa haemorrhagica: Clinical and laboratory features in 30 patients. Oral Surg Oral Med Oral Pathol 1987;63:560-5

9. Gibson J. Oropharyngeal blood blisters are known as angina bullosa haemorrhagica. BMJ 1997;314:1625-7.

10. Pahl C, Yarrow S, Steventon N, Saeed NR, Dyar O. Angina bullosa haemorrhagica presenting as acute upper airway obstruction. Br J Anaesth 2004;92:283-6.

11. Grinspan D, Abulafia J, Lanfranchi H. Angina bullosa hemorrhagica. Int J Dermatol 1999;38:525-8. 